\title{
O Discurso Meritocrático nas Explicações Parentais de Crianças com Queixa Escolar
}

\author{
Mariana Inés Garbarino ${ }^{1}$ \\ ${ }^{1}$ Universidade Federal de São Paulo, SP, Brasil.
}

Resumo: $\mathrm{O}$ artigo discute a leitura meritocrática do fracasso escolar e mapeia sua emergência no discurso de participantes de um programa de extensão universitária que atende crianças com queixa escolar. Indaga-se a dimensão social do discurso sobre dificuldades de aprendizagem explorando e comparando de que modo esta ressoa nas tramas significantes de crianças e adultos. Foram analisadas 128 fichas de inscrição onde os sujeitos assinalaram o motivo da demanda de atendimento. Com base em análise qualitativa e quantitativa (não estatística) das produções discursivas, reflete-se acerca da coconstrução dos sentidos da queixa escolar. Os resultados mostram que, diferentemente dos motivos infantis, o discurso causal dos adultos tende a ser individualizante, o que se expressa na responsabilização da criança pelo "não aprender" justificada, predominantemente, por problemas de concentração e atenção. Concluiu-se que esses dados são coerentes com a atual lógica fragmentadora oriunda do crescente fenômeno da medicalização da infância, que desloca o conflito escolar para o âmbito da saúde mental.

Palavras-chave: Fracasso Escolar, Meritocracia, Queixa Escolar.

\section{Meritocratic Discourse in Explanations Provided by Parents of Children with School Complaints}

\begin{abstract}
This paper discusses the meritocratic interpretation of school failure and maps its emergence in the discourse of participants in a university extension program that serves children with school complaints. The social dimension of the discourse about learning difficulties is explored by comparing how this resonates in the significant narratives of children and adults. A total of 128 registration forms recorded their reason for the demand of a clinical care and were subsequently analyzed. Based on a qualitative/quantitative (non-statistical) analysis of discursive expression, this paper reflects on the co-construction of meanings present in school complaints. The results show that, unlike children's motives, the causal discourse of adults tends to be individualizing, which is expressed in the child's accountability for "not learning" being justified, predominantly, by problems of concentration and attention. These data are consistent with the current fragmented logic stemming from the growing phenomenon of childhood medicalization that shifts the school conflict to the mental health field.
\end{abstract}

Keywords: School Failure, Meritocracy, School Complaint. 


\title{
El Discurso Meritocrático en las Explicaciones Parentales de Niños con Queja Escolar
}

\begin{abstract}
Resumen: El artículo discute la lectura meritocrática del fracaso escolar y traza su emergencia en el discurso de participantes de un programa de extensión universitario que atiende a niños con queja escolar. Se indaga la dimensión social del discurso sobre dificultades de aprendizaje explorando y comparando de qué modo resuena en las tramas significantes de niños y adultos. Se analizaron 128 fichas de inscripción en las cuales los sujetos indicaron la razón de la demanda de atención. Con base en el análisis cualitativo y cuantitativo (no estadístico) de las producciones discursivas, se reflexiona acerca de la coconstrucción de los sentidos de la queja escolar. Los resultados muestran que, diferentemente de razones infantiles, el discurso causal de los adultos tiende a ser individualizante, lo que se expresa en la responsabilización del niño por su "no aprendizaje" justificada predominantemente por problemas de concentración y atención. Se concluye que esos datos son coherentes con la actual lógica fragmentaria que proviene del creciente fenómeno de medicalización de la infancia, que traslada el conflicto escolar para el ámbito de la salud mental.
\end{abstract}

Palabras clave: Fracaso Escolar, Meritocracia, Queja Escolar.

\section{Introdução}

Em 2015 o Censo Escolar brasileiro apontou um total de 3 milhões de crianças e jovens entre 4 e 17 anos fora da escola. Nesse mesmo ano, 1,6 milhões de alunos que apareciam matriculados no Censo de 2014 abandonaram a escola, sendo denominados pelo próprio

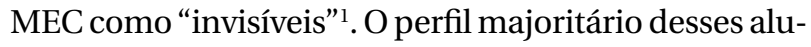
nos era de sexo masculino, negros e de escolas urbanas. Esse perfil converge com as estatísticas que revelam os três fatores que mais impactam no Ideb²: nível socioeconômico, cor/raça e gênero (Alves \& Soares, 2013). Em uma perspectiva diacrônica, o Ideb tende a diminuir significativamente nos anos finais do ensino fundamental, o que afeta mais os alunos não brancos por incidência de reprovação ou abandono precoce.

A precarização do ensino ao longo dos anos também se revela na relação significativa entre o Ideb e a infraestrutura física escolar, que vai dos equipamentos, como computadores e biblioteca, à manutenção do prédio, como presença de água tratada, banheiro, coleta de lixo, eletricidade, esgoto etc. (Alves \& Soares, 2013). No escopo nacional, os dados do Ideb também mostram melhor qualidade da aprendizagem nas escolas privadas em comparação com as públicas ${ }^{3}$. Os índices também tendem a ser mais elevados nos estados "mais ricos" em relação aos "mais pobres": Bahia, Amapá, Maranhão apresentam os níveis mais baixos, enquanto São Paulo e Minas Gerais, os mais elevados.

Mesmo diante da expressividade desses dados, as explicações meritocráticas e biologizantes em torno do fracasso escolar continuam presentes no cotidiano dos seus atores (Ochoa \& Orbeta, 2017), embora no campo acadêmico já tenha sido alvo de inúmeras críticas. A perspectiva da Sociologia da Educação de Pierre Bourdieu, surgida na França nos anos 1960, foi uma das primeiras a evidenciar que crianças de classes socioeconômicas mais pobres não só ingressam "desfasadas" em relação às habilidades que o sistema escolar supõe já prontas como pré-requisitos

\footnotetext{
1 Termo utilizado pelo então ministro de Educação Aloizio Mercadante. Fonte: http://educacao.uol.com.br/noticias/2016/05/06/ governo-quer-localizar-16-milhao-de-alunos-que-deixaram-a-escola-em-2015.htm

2 Índice de Desenvolvimento da Educação Básica, criado em 2007 pelo Instituto Nacional de Estudos e Pesquisas Educacionais Anísio Teixeira (Inep) para medir a qualidade da aprendizagem nacional e estabelecer metas para a melhoria do ensino.

${ }^{3}$ A precarização do ensino na escola pública, bem como os maiores índices de evasão e repetência de seus alunos, não são fenômenos recentes, mas datam de finais do século XIX, praticamente de modo simultâneo à própria origem da escola (Patto, 2000; Paula \& Tfouni, 2009). Porém sabemos que sua manifestação se modela sob formas específicas de laço social e tensões de acordo com a conjuntura.
} 
para aprender, mas a situação de desigualdade social na qual estão inseridas é perpetuada e legitimada na escola (Nogueira \& Nogueira, 2002). Um dos elementos estruturais dessa discrepância de classe se expressa na linguagem utilizada pelos alunos, oriunda de diferentes níveis de capital cultural e simbólico herdados da família, e que pode ser mais ou menos compatível com aquela exigida e reivindicada pela escola.

O mito da igualdade de oportunidades e a crença vigente na legitimidade do mérito foram problematizados posteriormente por vários autores (Dubet, 2005; Stiglitz, 2012). Pesquisas recentes têm mostrado que as diferenças de classe não se "neutralizam" ao ingressar na escola e que, por exemplo, estudantes pobres, mesmo quando apresentam melhor desempenho escolar que os ricos, têm menos chances de acessar a universidade, cuja população prevalecente é oriunda das minorias com maior poder aquisitivo (Stiglitz, 2012).

$\mathrm{O}$ fracasso escolar resulta em um sentimento de insucesso coletivo que toma conta dos atores envolvidos em seu cotidiano: a criança, sua família e os professores. Entretanto as parcelas de responsabilidade costumam ser repartidas em diferentes graus. Nesse sentido, o falso dilema de apontar a causa do fracasso na origem familiar de crianças pobres ou na escola que frequentam oculta o fato de que ambos os fatores são, em realidade, prismas de um mesmo fenômeno mais abrangente de desigualdade social. A partir de uma perspectiva dialética, tal como apontado por Paín (2010), a aprendizagem é um processo social complexo, vivenciado por sujeitos que são, simultaneamente, produtos de um momento histórico, um corpo, uma etapa genética da inteligência, uma história libidinal e um conjunto de crenças, saberes e práxis culturais.

No campo acadêmico as dificuldades escolares constituem um tema de crescente interesse em pesquisas das áreas da Psicologia, Medicina, Educação, Sociologia e Psicopedagogia. Dependendo da área de conhecimento e da linha teórica escolhida, tem-se como foco o mal-estar institucional dos atores escolares, o fracasso escolar e suas relações com políticas públicas, as implicações dos discursos de pais e professores no autoconceito dos alunos, os problemas de relacionamento e disciplina no cotidiano escolar e a avaliação e intervenção no atendimento das dificuldades e transtornos da aprendizagem. Diante da dificuldade de conceber de forma mais holística essas dimensões sempre presentes na situação de ensino-aprendizagem, os estudos psicológicos sobre o "não aprender" podem realizar uma fragmentação e redução do problema a questões disfuncionais do sujeito. Além disso, a terminologia utilizada muitas vezes se apresenta de forma ambígua, não sendo fácil distinguir sua especificidade. De modo geral, podem ser observados três grandes grupos de termos: distúrbios elou transtornos da aprendizagem, dificuldades de aprendizagem e queixa escolar.

A primeira denominação tem sua origem nos manuais psiquiátricos de critérios diagnósticos e pressupõe uma disfunção dos circuitos cerebrais que prejudicaria um domínio de habilidades (manifestada em transtornos como discalculia, disgrafia, disortografia etc.). A massificação do prefixo "neuro" em termos como neuropsicopedagogia, neuroaprendizagem e neuroeducação ${ }^{4}$ vem se instalando com força e instiga novas questões acerca do sentimento contemporâneo de infância e da abordagem de suas problemáticas e supostos "desvios". Esse fenômeno resulta impulsionado pelo expressivo aumento da influência da indústria farmacêutica direcionada aos transtornos do neurodesenvolvimento na infância. Sua presença apresenta peculiaridades regionais. Por exemplo, no caso do transtorno de déficit de atenção e hiperatividade (TDAH), na Argentina o marketing tende a ser direcionado para pais e professores, e no Brasil para os grupos de apoio de sujeitos com transtornos (Bianchi \& Farone, 2015; Bianchi, Ortega, Faraone, Gonçalves, \& Zorzanelli, 2016). A medicalização da infância é, dessa forma, um produto sociocultural, com práticas de diagnósticos classificatórios e discursos explicativos modelados por características histórico-políticas próprias de cada país. Assim, o discurso das neurociências permeia e oferece legitimidade científica às concepções contemporâneas de escolarização e de saúde (Guarido, 2007).

\footnotetext{
${ }^{4}$ A neuroeducação ou neurociência do aprendizado estuda "a organização dos circuitos funcionais das células nervosas, que processam a informação e medeiam o comportamento", valendo-se de instrumentos como a ressonância magnética funcional para estudar o cérebro em atividade (Fernandes, Muniz, Mourão-Carvalhal, \& Dantas, 2015, p. 396). Refere-se a um campo multidisciplinar de conhecimento e de atuação profissional, nas áreas da docência e da pesquisa educacional, que deverá ser assimilado por um novo perfil de educadores que considerará as neurociências ao planejar e desenvolver seus projetos de ensino e de aprendizagem (Zaro et al., 2010).
} 
Nessa conjuntura, à psicometria que coisificava o sujeito avaliado e justificava cientificamente sua exclusão social (Patto, 1997), soma-se hoje a medicação, elemento que acarreta mudanças no vínculo professor-aluno (Bonadio \& Mori, 2013; Guarido, 2007). Dentre elas, pode se mencionar a recorrente explicação causal das mudanças de humor das crianças medicadas com base na suposição de uma incorreta dosagem de medicação, deixando de lado fatores alheios ao transtorno como conflitos oriundos do cotidiano escolar (Guarido, 2007). Em síntese, dois problemas levantados pela literatura são destacados. Por um lado, a passagem direta entre descobertas das neurociências a um método de ensino (a neuroeducação) e, por outro, a transformação do rótulo de criança "preguiçosa" ou "desinteressada" a "portadora de um transtorno", o que, na prática, teria levado ao deslocamento de punições a tratamentos psiquiátricos (Brzozowski \& Caponi, 2013).

A designação dificuldades de aprendizagem aponta problemas episódicos ou temporários que podem ser resolvidos com mudanças de metodologia de ensino, terapias psicológicas e psicopedagógicas, ou seja, com intervenções pontuais. Dentre os fatores de risco para as dificuldades de aprendizagem, encontram-se o maltrato, a rigidez, o autoritarismo, o excesso de crítica, a hipoestimulação no lar e a frequente mudança de professores (Sabina, Saéz, \& Roméu, 2010). Ademais, essas questões constituem um fator de risco para problemas psicossociais. Entretanto, a carência de estudos longitudinais impede de se identificar quais fatores de risco são desencadeantes, intensificadores ou consequências das dificuldades de aprendizagem. Na literatura, por exemplo, o déficit de habilidades sociais aparece tanto no lugar de causa como no de consequência (Mazer, Bello, \& Bazon, 2009).

Já o termo queixa escolar foca o processo de desnaturalização e historização das dificuldades de aprendizagem a partir de uma avaliação crítica da sua leitura individualista, apontando seu caráter de produto institucional e político (Autor, 2017). Nesse sentido, esse terceiro grupo de abordagem vem corroborando que os avanços da indústria farmacêutica e sua relação com o fenômeno da medicalização da infância, especialmente a partir do diagnóstico de TDAH, trazem efeitos discursivos e práticos nos planos familiar e escolar, tais como a culpabilização da criança pela não aprendizagem (Asbahr \& Lopes, 2006).
O vocábulo medicalização define o crescente processo de deslocamento de conflitos de ordem social e política ao campo da medicina, sendo assim abordados como problemáticas individuais e, majoritariamente, biológicas (Untoiglich, 2014). O termo foi cunhado na década de 1970, e em grande parte deve sua fecundidade e desenvolvimento aos estudos de Foucault (Carvalho, Rodrigues, Costa, \& Andrade, 2015). A dimensão mercadológica desses diagnósticos comprova-se no crescente marketing da indústria farmacêutica, editorial e midiática, intimamente relacionados com a prática da psicologia (Bianchi et al., 2016; Giusti, 2016). Desse modo, considera-se que, se em outros tempos a raça e a carência cultural eram os argumentos explicativos do fracasso escolar, a responsabilização se coloca hoje na própria criança (Asbahr \& Lopes, 2006; Giusti, 2016; Guarido, 2007; Patto, 1997; Paula \& Tfouni, 2009; Proença, 2002; Untoiglich 2014).

A atual construção das tramas significantes hegemônicas que pretendem explicar o insucesso escolar versa entre a naturalização e a patologização, o que se manifesta especialmente na pulverização de transtornos do desenvolvimento e da aprendizagem (Ceardi, Améstica, Núñez, López, \& Gajardo., 2016; Untoiglich, 2014). O fenômeno resulta correlato à tendência de atribuição causal endógena acerca das dificuldades escolares. Desde uma perspectiva piagetiana (1926/2005), por exemplo, essa crença causal responderia a uma lógica pré-operatória do pensamento que se concentra no plano do aparente, do imediato e em uma parte do todo (da criança no aqui e agora), dando assim um tom mágico, arbitrário e imanente à realidade social.

A crescente circulação desse discurso na escola proporciona terminologias que nomeiam e classificam os alunos. Conforme Rosa (2013), o excesso de significado oferece o caráter absoluto de uma suposta "verdade" inteira e última, da certeza opaca da ignorância na direção oposta do desejo de saber, que supõe o enigma e a incógnita. Desde essa ótica do enigma, um diagnóstico faz parte da construção de uma história subjetiva que não se reduz a uma mera sequência de dados, mas que envolve tramas de significâncias e de sentido. Especificamente em relação ao diagnóstico de discalculia, Bernardeau, Devaux, Josso-Faurite e Scalabrini (2014) estudaram seus efeitos subjetivos afirmando que este acaba funcionando como uma etiqueta que confirma um fracasso, em vez de abrir perguntas sobre a criança. 
Os efeitos subjetivos do paradigma neurocientífico não só provêm dos diagnósticos, mas também do discurso dos professores. Ao entrevistar alunos com dificuldades de aprendizagem, Osti e Brenelli (2013) evidenciaram que eles manifestam uma representação negativa de si mesmos e nutrem baixas expectativas sobre seu desempenho escolar, vivenciando este como uma experiência tensa. Uma parte dessas crianças considerou que suas professoras entendiam que suas dificuldades provinham de alguma "doença na cabeça”, de um problema no cérebro, ou que eram consequência de uma "cabeça que não funciona direito", o que foi expresso em frases como: "a prô diz que eu tenho problema no cérebro e que não aprendo", "quem não aprende tem problema do cérebro" (Osti \& Brenelli, 2013, p. 420-421). Observa-se assim que, seja de modo sutil ou explícito, o fenômeno da medicalização da infância se presentifica no cotidiano dos discursos escolares, encarnado em seus atores (seja professores, crianças e famílias) e impregnando seus imaginários acerca do "não aprender". A sua reprodução no cotidiano escolar acaba, por sua vez, fortalecendo a patologização da aprendizagem (Untoiglich, 2014).

Os impactos do discurso dos transtornos na educação escolar configuram um tema atual e relevante, visto que os problemas na escola continuam sendo o principal motivo de encaminhamento de crianças entre 6 e 10 anos para atendimentos de saúde mental (Proença, 2002; Zulueta, 2010). Medicalização e mal-estar escolar aparecem entrelaçados, sendo a escola o palco onde se costuma fazer mais evidente a "desordem" da criança na ordem instituída e a consequente necessidade de amenizar sua desadaptação. A escola aparece na literatura como uma das instituições responsáveis, ainda que de maneira indireta, pelo aumento da medicalização na infância, especialmente ao incentivar diagnósticos como o TDAH visando que o tratamento medicamentoso deixe os alunos mais calmos (Ceardi et al., 2016; Leavy, 2013; Observatório Argentino de Drogas, 2008).

O ingresso do discurso científico na escola também se expressa na prática de pré-diagnósticos do professorado, o que dificulta a análise das matrizes institucionais da dificuldade de aprendizagem que se encarnam no aluno, mas que o transcendem (Aquino, 1997). A justificativa da carência dessa análise crítica é complexa, podendo-se se dever a diversos fatores, como a precarização da formação docente. A respeito dessa prática, Guarido (2007) destaca a frequência com que professores e coordenadores pedagógicos professam diagnósticos (especialmente de TDAH) com base na observação de certos comportamentos, tais como agitação e desatenção, que justificam o encaminhamento de alunos para avaliação psiquiátrica, neurológica, psicológica e/ou fonoaudiológica. Além disso, a denominação distúrbios/transtornos de aprendizagem, oriunda do discurso médico-psiquiátrico, é frequentemente mencionada nos relatórios e falas dos professores. Mas essa categoria diagnóstica resulta vaga e abrangente porque acaba patologizando aspectos conflitivos que são inerentes ao cotidiano escolar pela complexidade da relação professor-aluno, da adequação das intervenções pedagógicas e das características da aprendizagem e do desenvolvimento infantil. Desse modo, o termo transtorno facilita a tendência de enquadrar qualquer criança que apresenta dificuldades na escola (Machado, 1997).

Atualmente, a recorrente queixa pela falta de atenção, esforço e concentração dos alunos configura um dos principais desvios do perfil ideal esperado. Segundo Arbisio (1997/2007), "o fracasso escolar põe em perigo a imagem magnificada de uma criança dócil e estudiosa, e cada época utilizou seus parâmetros ideológicos para explicar o desvio em relação ao ideal" (p. 248). A demanda de esforço e atenção à criança deixa de lado o lugar dos adultos na construção dessas competências. Fernandez (2012) definiu que o desenvolvimento da "capacidade atencional" configura-se no modo como o sujeito está sendo atendido pelos outros. Portanto, a atenção assume formas e modalidades específicas que são mediadas pelo contexto cultural de acordo com cada época histórica. Essa tese defendida por De-Nardin e Sordi (2007) assinala que a saturação, velocidade e excesso de informação da era tecnológica se entrelaçam com marcas sociais de individualismo e competitividade. Nesse contexto, e especialmente a partir da década de 1990 com os diagnósticos de TDAH, a atenção foi entendida como a condição protagonista para aprender, em concordância com o aumento das estratégias de marketing da indústria farmacêutica (Bianchi et al., 2016).

Em resumo, se a atual proliferação de classificações diagnósticas e de queixas por falta de atenção e concentração oculta a complexidade do fracasso escolar, o resgate da sua dimensão sócio-política e histórica problematiza essas leituras reducionistas, introduzindo aspectos éticos na sua prática e alertando para interpretações reprodutoras da 
patologização da aprendizagem. Nessa perspectiva, o fracasso escolar constitui a "dimensão sociopolítica do sofrimento" (Rosa, 2013) das crianças que encarnam esse fenômeno e tendem a ser responsabilizadas pelo "não aprender".

\section{Esforçado versus inteligente: a responsabilização da criança pela sua aprendizagem}

Em termos de desenvolvimento psíquico, a circulação exacerbada e deformada do discurso dos transtornos na escola vem fomentando a construção de um si mesmo cognoscente desvalorizado e fragilizado. Isso em função de que a atribuição causal do transtorno remete à dimensão de capacidade ou atitude da criança. Nesse sentido, pesquisas da psicologia sociocognitiva contribuíram para observar e analisar aspectos socioafetivos implicados nas dificuldades escolares, tais como a autorregulação e o desenvolvimento metacognitivo no contexto acadêmico (Polydoro \& Azzi, 2008).

No vasto levantamento realizado por Cabanach e Arias (1998) são mencionadas características afetivo-emocionais comparativas entre alunos com e sem dificuldades de aprendizagem. Essa caracterização é referente à atribuição causal do seu sucesso e fracasso escolar. Os grupos apresentam diferenças em relação a quatro variáveis inspiradas na clássica teoria atribuicional da causalidade (Weiner, 1985): capacidade, esforço, acaso e influência dos outros. Dependendo da atribuição escolhida, cada pessoa pode experimentar sentimentos diversos. O Quadro 1 sintetiza essa relação entre atribuição causal e emoções.

Considerando o Quadro 1, caso a criança atribua a causa do seu fracasso escolar à falta de capacidade, ela seria mais vulnerável para desenvolver uma baixa autoestima por este ser considerado um fator incontrolável e estável. Já a explicação do insucesso por falta de esforço seria motivadora de culpa por ser uma atribuição interna, mas controlável, ou seja, que pode ser modificada. Os alunos com dificuldades de aprendizagem tendem a explicar seus fracassos acumulados por meio de um padrão atribuicional de baixa capacidade (Cabanach \& Arias, 1998; Martinelli \& Grecci Sassi, 2010). Por um lado, essa atribuição promove sentimentos negativos na motivação e, por outro, reduz as expectativas futuras de sucesso, o que favorece a perda de confiança nas próprias capacidades (Silva, Beltrame, Viana, Capistrano, \& Oliveira, 2014). A repetição de experiências escolares negativas diminui o autoconceito e o esforço, o que pode levar a retraimento social e/ou comportamentos desadaptativos. Assim, a não implicação nas tarefas favorece novos fracassos, o que leva a um "círculo de desamparo" (Cabanach \& Arias, 1998).

Ao enfoque intrapessoal da motivação de Weiner (1985), acrescentam-se os aspectos interpessoais das atribuições causais de pessoas significativas do entorno do aluno. Nessa linha, pesquisas realizadas com professores da escola pública (Bzuneck \& Sales, 2011) mostraram que a causa do fracasso tende a ser atribuído aos alunos, sendo a ação docente reconhecida como um fator de aprendizagem só nas situações de sucesso escolar, crença que leva a sentimentos de impotência nos professores. Feschler (2012) conjetura que a atitude defensiva que visa se responsabilizar só pelo sucesso responde à preservação do narcisismo tanto dos professores como dos pais. Portanto, a escola atualmente não enfrentaria a pergunta pela responsabilidade dos adultos diante da dificuldade escolar.

\section{Quadro 1}

Sentimentos consequentes à atribuição causal de fracasso ou sucesso.

\begin{tabular}{|c|c|c|c|c|c|}
\hline $\begin{array}{l}\text { Atribuição } \\
\text { causal }\end{array}$ & Situação de fracasso & Situação de sucesso & $\begin{array}{l}\text { Possibilidade } \\
\text { de controle }\end{array}$ & Estabilidade & Lócus \\
\hline Esforço & culpa & calma (relaxamento) & controlável & instável & interno \\
\hline Capacidade & $\begin{array}{l}\text { Incompetência } \\
\text { (baixa autoestima) }\end{array}$ & $\begin{array}{l}\text { Competência (orgulho, } \\
\text { alta autoestima) }\end{array}$ & incontrolável & estável & interno \\
\hline Sorte & surpresa & surpresa & incontrolável & instável & externo \\
\hline $\begin{array}{l}\text { Influência } \\
\text { dos outros }\end{array}$ & ira & gratidão & incontrolável & estável & externo \\
\hline
\end{tabular}

Fonte: Elaboração própria com base nas categorias de Weiner apresentadas por Cabanach e Arias (1998). 
Entretanto, os alunos continuam dando especial importância à interpretação dos professores e colegas sobre seu desempenho (Osti \& Brenelli, 2013). Em função disso, em alguns casos os estudantes preferem ser vistos como preguiçosos a serem considerados incapazes, e, em outros, optam por gerar compaixão, expressando empenho para deixar claro que a causa do fracasso deve-se a incapacidade (Bzuneck \& Sales, 2011). Nesse contexto, a intervenção adulta que dá ênfase discursiva na demanda de um aumento do esforço é uma questão controversa. Se um aluno considera ter se esforçado ao máximo, mas recebe do professor a interpretação de que fracassou porque faltou esforço, ele poderá então explicar seu desempenho em termos de incapacidade (Martini \& Del Prette, 2002).

Ademais, de acordo com o Quadro 1, a atribuição causal de falta de esforço nas situações de fracasso pode levar a sentimentos de culpa. A esse respeito, Dweck (2015) afirma que é fomentado um olhar negativo do esforço quando se acredita que é evidência de pouca inteligência, como se as pessoas "inteligentes" não precisassem se esforçar. Ainda que o esforço seja chave para o estudo, as crianças precisam de novas estratégias para não ficar estancadas, ou se esforçando com um repertório errado. Mas outro ponto também problematizado pela autora é o excesso de "consolo" e elogios do tipo "parabéns, você se esforçou tudo o que pôde" para que elas se sintam bem, mesmo quando não estão aprendendo nem melhorando.

Em síntese, explicar a dificuldade escolar por insuficiência de esforço ou de capacidade termina reduzindo o problema na criança. As produções discursivas sobre sua causalidade interferem, reciprocamente, no processo de construção do si mesmo pensante e do posicionamento subjetivo diante dos conflitos cognitivos e interpessoais, na escola e fora dela. Em outras palavras, as restrições, fraturas e inibições na produção simbólica dos alunos também estão correlacionadas com os modos de interpretar a realidade e de se relacionar com o mundo (Schlemenson, 2009).

Diante da diversidade de fatores envolvidos na queixa escolar, e partindo do princípio interacionista da co-construção indivíduo-entorno, a presente pesquisa visou contribuir para melhor entender a gênese das crenças em torno do "não aprender" por parte de crianças e adultos, comparando de que modo a leitura meritocrática do fracasso ecoa em seu discurso e problematizando os possíveis efeitos subjetivos dessa interpretação. O trabalho buscou identificar esses sentidos predominantes nos motivos de inscrição de participantes de um programa de extensão universitária que atende crianças com queixa escolar. O preenchimento das fichas de inscrição, por parte de crianças e adultos, constitui a primeira apresentação na forma de demanda a outro. Considerando o atual debate sobre a queixa escolar, a consulta desses materiais não teve como objetivo desvendar as causas das dificuldades, mas contribuir nas seguintes questões: quais são os sentidos prevalentes acerca da queixa escolar na ótica das crianças e dos adultos? Se há diferenças entre ambos, o que as explicaria? De que modo os discursos meritocráticos e os significantes provenientes da neuropsiquiatria permeiam a demanda de atendimento?

\section{Método}

\section{Dispositivo e participantes}

A pesquisa foi realizada em um Programa de Intervenção com jogos que, desde 1989, funciona como atividade de extensão universitária. Atende crianças de 7 a 11 anos com queixa escolar que, majoritariamente, frequentam escolas públicas ou fundações. Os materiais obtidos dos arquivos são referentes a sete semestres de atendimentos, realizados entre 2011 e 2014. O sexo das crianças da amostra foi maioritariamente masculino, o que se corresponde com a histórica prevalência de meninos na procura do atendimento. Frequentavam Ensino Fundamental I, do $1^{\circ}$ ao $5^{\circ}$ ano. As famílias eram de classe socioeconômica média e baixa, provenientes da Grande São Paulo e outras localidades. Os longos deslocamentos para garantir o atendimento com "profissionais da Universidade X" refletia, por uma parte, a boa reputação institucional da universidade e, por outra, a carência de opções de espaços de atendimento gratuito ofertados pela Secretaria de Ensino ou pelo SUS.

A demanda com que a criança chega é diversificada conforme a prevalência de dificuldades na alfabetização e/ou matemática, queixas por dispersão, falta de interesse, desatenção, problemas de relacionamento e disciplina, e diagnósticos de transtornos específicos ou síndromes (suspeita ou diagnóstico de TDAH, dislexia etc.). A pesquisa foi submetida e aprovada pelo Comitê de Ética em Pesquisa com Seres 
Humanos (CEPH), conforme parecer no 1.082.789. Para manter o anonimato, os participantes $(\mathrm{P})$ foram identificados com um número e o sexo entre parêntese.

\section{Instrumentos}

Foram analisadas 128 fichas de matrícula com os motivos de inscrição escolhidos para explicar a solicitação de atendimento. A ficha é preenchida no início de cada semestre e contém espaços para dados pessoais como nome, endereço, telefones etc. Quando a criança não consegue escrever (porque diz não saber o motivo de inscrição ou por dificuldade na escrita), ela leva a ficha para casa para ser preenchida por um adulto ${ }^{5}$.

\section{Procedimentos para a análise de dados}

A análise e comparação das produções visaram sistematizar os motivos da inscrição para melhor compreender as preocupações mais destacadas das crianças e dos familiares. Foi realizada uma análise qualitativa e quantitativa (não estatística) das informações escritas nas fichas de matrícula, e, para isso, a técnica escolhida centrou-se na análise de conteúdo. Conforme seus fundamentos básicos (Castro, Abs, \& Sarriera, 2011), o material foi lido exaustiva e minuciosamente para identificar os temas convergentes das fichas. A codificação do conteúdo da escrita focalizou a observação dos principais qualificadores e descritores das causas da queixa escolar escolhidos pelos participantes (palavras como atenção, concentração, ler, escrever). Com base nessas unidades de registro, postularam-se cinco categorias de motivos de inscrição. Por último, os dados foram categorizados e organizados em tabelas de frequência percentual, e foram inferidas as tendências de interpretação de adultos e crianças sobre a queixa escolar. A seguir, expõem-se os significados e atribuições causais que circularam com maior frequência em suas produções discursivas.

\section{Resultados}

Das 128 fichas de matrícula consultadas, 82 foram preenchidas pelas próprias crianças e 46 por adultos (pais ou responsáveis de participantes). Após leitura sistemática, as respostas foram organizadas em cinco categorias, conforme se vê no Quadro 2.

\section{Quadro 2}

Categorias de organização para os motivos de inscrição de adultos e crianças.

Cognitivo ou escolar

Atitudinal ou comportamental

Mistos

Encaminhamento e/ ou diagnóstico
Menção de habilidades cognitivas, competências acadêmicas ou metas exigidas na escola, como ler/escrever, tirar boas notas, aprender, estudar etc. (ex. ajuda para ler/para melhorar na escola/aprender/para lição de casa).

Referência a atitudes atuais restritivas, como dispersão, pouca atenção e concentração, ou expectativas de mudança (ex. ficar mais corajoso). Indícios de autorresponsabilidade pelas dificuldades (ex. porque converso muito).

Alusão a motivos cognitivo-escolares e atitudinais.

Menção de demanda externa, encaminhamento da escola ou profissional da saúde (ex. $A$ escola pediu para fazer psicopedagogia / TDAH).

\footnotetext{
${ }^{5}$ Por esse motivo, as tendências exploradas na pesquisa não correspondem à dupla pais-filhos. A análise comparativa de explicações de crianças e adultos com vínculo familiar seria extremamente interessante como objeto de estudo de futuros trabalhos.
} 


\section{"Pra aprender a ler e escrever": os motivos das crianças}

Com base nas categorias supracitadas, apresenta-se a seguir a distribuição dos motivos preenchidos pelas crianças participantes das oficinas nas 82 fichas de matrícula.

\section{Tabela 1}

Frequência absoluta e percentual de tipos de motivos das crianças.

\begin{tabular}{lcc}
\hline Tipos de motivos & $\mathrm{N}$ & $\%$ \\
\hline Cognitivo-escolar & 53 & 66 \\
Atitudinal & 11 & 13 \\
Mistos (cognitivo + atitudinal) & 1 & 1 \\
Encaminhamento e/ou diagnóstico & 6 & 7 \\
Outros & 11 & 13 \\
\hline Total & 82 & 100 \\
\hline
\end{tabular}

Os motivos levantados pelas crianças são, em geral, muito breves (em parte pela frequente dificuldade na escrita), no entanto, as informações permitiram inferir tendências de interpretação sobre a própria dificuldade escolar. Das 53 fichas preenchidas que mencionam questões cognitivo-escolares, 16 especificaram problemas relacionados a alfabetização, e só duas mencionaram a matemática. Os recorrentes motivos "para aprender a ler"/"para aprender a escrever" evidenciaram uma preocupação significativa e uma expectativa da criança em relação a sua alfabetização. As fichas restantes apelaram a motivos menos específicos como "para aprender", "para melhorar na escola", "para fazer lição de casa" etc.

Cabe lembrar que a participação em um programa de intervenção não deriva de uma escolha espontânea das crianças. Elas são sempre levadas pela família, que por sua vez são "levadas" por uma queixa escolar. No desenrolar do atendimento, cada uma se apropria de forma singular do espaço e das dinâmicas, de modo mais ou menos autônomo em relação aos encaminhamentos dos professores e às expectativas parentais. As crianças chegam com ideias diversas transmitidas pelos adultos que relacionam o atendimento a um espaço educativo, de cura ou de recreação, tal como nas expressões a seguir: P1(M), " minha mãe acordou e disse que o avó ia trazer na (universidade) para estudar"; $\mathrm{P} 2$ (M), "meu pai falou que eu ia no médico. Eu não gosto desses atendimentos”; P3 (M), "minha mãe falou que ia na (universidade) para brincar".

Dentre os motivos atitudinais mencionados pelas crianças prevalecem a dispersão, a desconcentração e a conversa em sala de aula, como no caso de P4 (M): "porque eu converso demais". Problemas de relacionamento também foram manifestados: P5 (M), "não ficar nervoso quando alguém me irrita”. Um posicionamento de culpabilidade foi expresso por P6 (M) em uma extensa escrita quase com caráter de confissão: "porque não estou prestando atenção na professora, estou brincando na aula, estou com dificuldades nas lições de casa, não estou conseguindo acompanhar a professora, estou com muita dúvida nas lições, eu não estou estudando muito".

Cada criança assimila os discursos dos adultos de um modo singular. No caso de P6 (M), o motivo de inscrição foi a estética da sua letra: "porque eu não sabia fazer letra bonita". Mesmo sendo possível que letra bonita signifique legivel, é interessante que ele tenha assimilado que sua letra era feia. $\mathrm{O}$ vocabulário escolhido pela criança também dá indícios de como o discurso sobre sua dificuldade é coconstruído, como no caso de P7 (F), que procurava "ter raciocínio, quantidade mais rápida”. Outro elemento saliente nas fichas foi a escrita de termos específicos de diagnósticos, inclusive com a nomenclatura de manuais de psiquiatria: P8 (M), "Para a apresentação F906 pedido conselho tutelar". Essa presença do discurso neuropsiquiátrico e dos diagnósticos na construção identitária da criança pode responder defensivamente a um problema narcisista ou de identidade, tal como apontado por Janin (2004). Para a autora, um rótulo de déficit, mesmo quando apaga o estatuto de sujeito, o nomeia como algo diferente que pode resultar melhor do que nada.

Somente uma das fichas apresentou alusão aos adultos, ao expressar: P9 (M), "porque estou com problemas familiares (minha mãe está com problemas inclusive com seu trabalho)". Entre os motivos relacionados à capacidade, P10 (F) escreveu: "para ficar mais inteligente", o que pode significar que ela se considera pouco inteligente para responder satisfatoriamente na escola, mas também a presença de uma expectativa de autossuperação. Nesse caso haveria a suposição de que a inteligência muda, diferentemente da

${ }^{6}$ F90: Transtornos hipercinéticos (CID 10) 
ideia de estabilidade do construto "capacidade" acima mencionada no contexto das pesquisas da teoria sociocognitiva (Quadro 1). Considerar-se insuficientemente capaz em um momento ou para determinada tarefa não implica, necessariamente, a ideia de imobilidade ou cronicidade dessa situação pontual. Assim, a atribuição causal referida a uma limitação em termos de capacidade precisa ser aprofundada para entender como é assimilada pelo sujeito.

\section{"Você é muito inteligente, mas tem preguiça": os motivos dos adultos}

Utilizando as mesmas categorias do Quadro 2, foram sistematizadas as manifestações dos adultos sobre os motivos de inscrição no atendimento.

Tabela 2

Frequência absoluta e percentual de tipos de motivos dos adultos.

\begin{tabular}{lcc}
\hline Tipos de motivos & $\mathrm{N}$ & $\%$ \\
\hline Cognitivo-escolar & 11 & 24 \\
Atitudinal & 9 & 20 \\
Mistos (cognitivo + atitudinal) & 13 & 28 \\
Encaminhamento e/ou diagnóstico & 13 & 28 \\
Outros & 0 & 0 \\
\hline Total & 46 & 100 \\
\hline
\end{tabular}

Comparada com a das crianças, a distribuição das respostas dos adultos é mais equitativa entre os diferentes tipos de motivos, expressando preocupação tanto com os aspectos atitudinais quanto com os cognitivos. Assim, em ambos os grupos observa-se que os entraves cognitivos-escolares resultam significativos; no entanto, como mostra a Tabela 1, estes são prevalentes entre as crianças (66\%). Somados os motivos mistos com os cognitivos, as porcentagens são de $67 \%$ para crianças e $52 \%$ para os adultos. Entretanto, somados os motivos mistos com os atitudinais, as porcentagens são de $14 \%$ para as crianças e de $48 \%$ para os adultos. Também são as famílias as que mais realizam menção a encaminhamentos da escola, o que pode ser interpretado como um deslocamento do saber e/ou da responsabilidade sobre a dificuldade dos filhos, ou como uma tentativa de estabelecer comunicação entre a escola e os profissionais do atendimento. Concordando com as informações oferecidas pelas crianças, dos 11 adultos que alegam dificuldades cognitivas, sete apontam problemas relacionados com a alfabetização e nenhum com matemática. Entre as atitudinais, seis mencionam problemas de disciplina e/ou de relacionamento com colegas.

A respeito da nomenclatura da neuropsiquiatria, verificaram-se uma menina com diagnóstico de TDAH (medicada com Ritalina), um menino com suspeita desse transtorno e duas crianças tomando antidepressivos. Nas fichas preenchidas pelos pais, as palavras hiperatividade e neuropediatra foram mencionadas em três ocasiões. Os vocábulos atenção e hiperatividade aparecem incorporados no cotidiano discursivo, o que ficou ilustrado quando, mesmo sem diagnóstico, assinalou-se que uma criança apresentava "um pouco de déficit de atenção".

Nas produções escritas dos adultos, o termo atenção surgiu em dois sentidos, como defeito ou excesso. No primeiro caso, como déficit e dispersão, e no segundo como um modo infantil de demanda ao outro, de querer dizer algo, na expressão "querer chamar a atenção". A mãe de P11 (M) externou essa dupla significação: "a maioria das vezes não presta atenção na aula, fica muito disperso"; "bom, o P11 eleé bem sapeca, tem que estar chamando a atenção a todo momento, então na maioria das vezes tem que castigá-lo". Em outro caso, revelou-se um defeito de atenção no foco da tarefa, e um excesso no entorno, ou seja, uma atenção seletiva que não responde à expectativa do adulto: "P12 é agitado, inquieto e disperso. Presta atenção em tudo o que acontece na sua volta e não no que está fazendo. Sabe, mas acaba fazendo errado".

A desmotivação e falta de interesse da criança também estiveram presentes no modo dos adultos justificarem a inscrição no atendimento, o que permitiu conhecer indícios das suas interpretações sobre as dificuldades dos seus filhos. Algumas frases ilustraram suas causas: "não sente interesse na leitura e escrita"; "falta de vontade de estudar"; "preguiça no aprendizado, não gosta de ler, aprender sobre as coisas, muito disperso. Só quer saber de brincar e copiar a lição e não quer aprender". Observaram-se alusões reiteradas ao prefixo "des" (que significa negação/privação): “desmotivação, desatenção, desorganização, despreocupação". Os motivos parentais em ocasiões também permitiram inferir concepções de aprendizagem, como na expressão: "Não grava o que aprende".

A Tabela 3 evidencia de forma mais clara a preocupação dos adultos, que se manifesta na sua maior escolha de motivos atitudinais quando comparado com as das crianças. 
Tabela 3

Comparação da frequência percentual dos motivos de inscrição de crianças e adultos.

\begin{tabular}{lcc}
\hline Tipos de motivos & Crianças & Adultos \\
\hline Cognitivo-escolar & 66 & 24 \\
Atitudinal & 13 & 20 \\
$\begin{array}{l}\text { Mistos } \\
\text { (cognitivo + atitudinal) }\end{array}$ & 1 & 28 \\
$\begin{array}{l}\text { Encaminhamento } \\
\text { e/ou diagnóstico }\end{array}$ & 7 & 28 \\
Outros & 13 & 0 \\
\hline Total & 100 & 100 \\
\hline
\end{tabular}

Dentro do escopo de motivos atitudinais referidos pelos dois grupos predominaram os vocábulos atenção e concentração. Também nas interpretações da escola $\mathrm{e}$ dos profissionais de saúde ${ }^{7}$ sobre as dificuldades houve convergência na utilização frequente dos termos atenção e concentração. O relatório escolar de P12 (M), além de mencionar dificuldades em português e matemática, acrescentou que o aluno "desconcentra-se com muita facilidade, de modo que qualquer movimento externo tira sua atenção". O relatório escolar de P13 (M) salientou que "por algumas vezes demonstra inquietude (...) grandes dificuldades de concentração". Das fichas preenchidas pelas crianças, quatro mencionaram falta de atenção, enquanto três aludiram a dispersão pela conversa com colegas, e duas a problemas de concentração. A Tabela 4 abaixo sintetiza a distribuição percentual das palavras atenção e concentração presentes nas fichas ${ }^{8}$.

\section{Tabela 4}

Frequência percentual dos termos atitudinais assinalados por crianças e adultos.

\begin{tabular}{lcc}
\hline Motivos atitudinais & Crianças & Adultos \\
\hline Atenção & 5 & 26 \\
Concentração & 3 & 22 \\
\hline
\end{tabular}

\section{Discussão}

Os dados mostraram uma clara diferença entre as tendências de atribuição causal das crianças e dos adultos, o que pode contribuir para contextualizar e repensar as avaliações e intervenções no atendimento da queixa escolar à luz das atuais pesquisas. Tal como observado nas tabelas, há uma reiterada menção a dificuldades de atenção e concentração por parte dos pais e de aspectos cognitivos por parte das crianças. Com base no levantamento da literatura já elencado, essa divergência pode ser interpretada em várias direções. Do lado dos adultos, pode-se lembrar o caráter disciplinar que os termos concentração e atenção tomam em expressões como "presta atenção!", intervenção recorrente no discurso de professores e pais (De-Nardin \& Sordi, 2007). Do lado das crianças, o fato de não assumir atitudes restritivas do aprender pode funcionar como uma defesa para proteger seu sentimento de autoeficácia e competência. Entretanto, a recorrência dos motivos infantis relacionados com a dimensão escolar e da aprendizagem nos leva também a deduzir uma denúncia simbólica ou pedido de ajuda. Em outras palavras, haveria uma demanda de atenção aos adultos para cumprir com seu papel de educadores e a manifestação de um desejo de aprender e "ficar inteligente" que não pode ser concretizado sem sua mediação.

Contudo, percebeu-se que, ao mesmo tempo que nas explicações dos adultos a causa do problema escolar não reside em uma questão de capacidade da criança, nem a escola nem os pais parecem se posicionar com claridade em torno do saber sobre a situação. Os encaminhamentos escolares delegam ao "outro especialista" a resposta para o enigma do não aprender. Na hora de agir diante desse conflito, os olhares ficam reduzidos à criança e as perguntas giram em torno de tentar descobrir o que está errado nelas apelando ao auxílio do discurso neurocientífico. Em convergência com essa interpretação unilateral, os materiais consultados convergiram, ademais, no destaque do esforço como o principal motor da mudança. O fomento da cultura do esforço pessoal, base do discurso meritocrático, parece se apresentar como a outra face do problema da atenção. Assim, prestar ou não prestar atenção é resultado do esforço de cada um, dinâmica que se ilustra no pressuposto de uma relação recíproca e diretamente proporcional "mais esforço = mais atenção" que sustenta a

\footnotetext{
${ }^{7}$ Vale ressaltar que somente algumas famílias disponibilizaram relatórios escolares e de profissionais da saúde. Porém o volume de material consultado nos permitiu identificar algumas tendências pertinentes para nossa análise.

${ }^{8}$ Ainda com a diferença apresentada nas Tabelas 3 e 4, em outras instâncias do atendimento, como no contexto das rodas de conversa, verificou-se que o discurso da atenção também está arraigado nas crianças, contrariamente ao que poderíamos inferir a partir dos dados até aqui mencionados.
} 
aprendizagem e o sucesso escolar. Como já foi assinalado, no Quadro 1, essa atribuição causal de falta de esforço nas situações de fracasso pode levar a sentimentos de culpa (Cabanach \& Arias, 1998; Martinelli \& Grecci Sassi, 2010). Além disso, ainda que o esforço seja chave para a aprendizagem, as crianças precisam da presença do adulto para construir novas estratégias e evitar insistir na tarefa com um repertório errado (Dweck, 2015).

Quando há cronicidade no estigma do "déficit", seja de atenção, capacidade ou esforço, esses rótulos conduzem a sentimentos de inferioridade, incapacidade e menos-valia, e o processo de escolarização gera sofrimento psíquico. Os alunos assim nomeados manifestam sentimentos de fracasso e uma autoimagem depreciativa de si mesmos (Cabanach \& Arias, 1998; Carneiro, Martinelli \& Sisto, 2003; Jacob, Loureiro, Marturano, Linhares, \& Machado, 1999; Osti \& Brenelli, 2013). A correlação entre autoconceito e desempenho dos alunos é diretamente proporcional (Sisto \& Martinelli, 2006). Conforme aumenta a dificuldade de aprendizagem, diminuem os sentimentos positivos, as crenças sobre a própria competência, a persistência diante das tarefas e as expectativas de êxito dos alunos. Essa retroalimentação é construída com base nas variáveis apontadas no Quadro 1, presentes em pesquisas que corroboram a existência de uma correlação altamente significativa entre elas (Cabanach \& Arias 1998).

Entretanto a relação entre dificuldades de aprendizagem e autoconceito escolar não pode ser estabelecida na forma de causalidade. Segundo Carneiro et al. (2003), não se sabe em que medida as experiências de fracasso escolar contribuem para a formação de um autoconceito escolar negativo, ou se a existência de um conceito de si mesmo mais negativo contribui para a configuração de situações de fracasso escolar. Todavia, pode-se afirmar que as crianças com dificuldades de aprendizagem costumam manifestar um autoconceito escolar mais rebaixado do que aquelas que não têm, o que leva a postular que o mais provável é que estes fatores estejam imbricados numa relação de mútua causalidade (Carneiro et al., 2003).

A coconstrução das interpretações presentes na queixa escolar toma especial relevância como objeto de pesquisa, sendo que durante o período denominado "segunda infância", entre os 6 e 10 anos aproximadamente, o principal motivo de consulta psicológica são demandas ligadas à escolaridade que contemplam problemas de adaptação e de aprendizagem (Lenoble, 2002; Zulueta, 2010). Mas quando as crianças chegam ao atendimento a demanda é do entorno, e não delas. Desse modo, a chegada de uma criança com queixa escolar a um atendimento de saúde é sempre permeado por diversos movimentos históricos que deram e dão lugar a modelos explicativos sobre a dificuldade na escola: da moralização às hipóteses neuropsiquiátricas, das explicações de tipo sociológico sobre a família e a instituição escolar às psicológicas (Arbisio 1997/2007; Untoiglich, 2014).

Portanto, na conjuntura dessas interpretações sócio-históricas, as competências que o aluno acredita possuir em relação a seu desempenho acadêmico são construídas, por um lado, com base nas experiências de sucesso ou fracasso vivenciadas na instituição escolar e, por outro, nas avaliações que recebe de seus professores, colegas e pais. A construção dessas crenças constitui um processo lento que se desenvolve nas experiências e relações com os outros, que aprovam ou desaprovam seu comportamento. Esses "outros" são, principalmente, os adultos cuidadores significativos que exercem algum controle sobre a criança e cujas opiniões têm influência sobre ela (Osti \& Brenelli, 2013; Sadalla, 1998). Nesse sentido, ao incentivar diagnósticos como o TDAH e legitimar o tratamento medicamentoso, a escola desloca o problema do "não aprender" do contexto escolar para o ambiente da saúde mental (Ceardi et al., 2016; Leavy, 2013).

Entretanto os resultados do presente trabalho apontam que as atribuições causais das crianças expõem ainda uma dimensão do "enigma" (Rosa, 2013) em detrimento da tentativa de fechar um diagnóstico sobre por que não estão aprendendo. Diferentemente dos adultos, os motivos infantis giram em torno da expectativa de ter sucesso na escola, aprender a ler e melhorar as notas, sem sentenciar ainda sua responsabilidade nesse intuito. A contribuição desses dados apresentam dois prismas de análise. Por um lado, a ideia de que essas crianças não estariam ainda em um registro de desgaste e dilapidação do autoconceito como alunos, entendendo que algo de errado está acontecendo e tem que mudar, mas sem necessariamente cair na dimensão da culpa pela falta de esforço, nem na ansiedade pela insuficiente capacidade para enfrentar os desafios escolares. Mas por outro lado, desde uma dimensão interventiva, é no próprio dispositivo de atendimento que se tenta 
promover um processo de tomada de consciência (Piaget, 1977) acerca de que atitudes e procedimentos singulares poderiam ser modificados para aprimorar a situação escolar (como conversar menos enquanto o professor fala, fazer a lição de casa etc.). Há assim uma fronteira sutil, mas que não pode ser desconsiderada, entre a culpabilização e a aceitação de uma parcela de responsabilidade e margem de ação entre a conjuntura escolar e a ação do sujeito.

A demanda de atendimento clínico costuma encarnar um pedido de ajuda ou orientação para amenizar o sofrimento psíquico, que, a princípio, emerge de conflitos na escola. Desempenho escolar insuficiente provoca preocupação nos pais e professores, mas também nos alunos. Dessa tensão entre o real e o esperado nascem sentidos causais e pressupostos acerca de por que essa criança não responde às expectativas dos adultos, que, ao serem frustrados, configuram a base da demanda. A crença no papel preponderante do esforço e da boa vontade pessoal como explicação causal do "se tornar inteligente" é coerente com a crença de que a desmotivação ou o desinteresse explicam o fracasso escolar, o que, consequentemente, o reduz a um fenômeno individual e biológico (Untoiglich, 2014).

Essa leitura unilateral de que o sucesso escolar depende só do aluno esconde o caráter social e coletivo da aprendizagem e também contradiz as teorias interacionistas clássicas do desenvolvimento. Conforme a teoria piagetiana, por exemplo, essa forma de entender o problema contradiz o postulado de que a afetividade (motivações, interesse, força de vontade) é necessária, mas não suficiente para o desenvolvimento cognitivo. Para Piaget, o bloqueio afetivo ou sentimento de inferioridade pode perturbar, dificultar ou atrasar o desenvolvimento cognitivo, mas não cria nem modifica suas estruturas (Piaget 1954/2000). Sem trocas sociais e experiências físicas de qualidade, o esforço individual é insuficiente para a construção operatória do conhecimento. Portanto, esforço, motivação e/ou interesse não explicam por si nem o sucesso nem o fracasso escolar.

Essa perspectiva piagetiana do desenvolvimento vai no avesso da psicometria e da medicalização da infância, que tendem, por uma parte, a amenizar o papel fundante das trocas sociais e, por outra, a coisificar o sujeito como objeto de estudo fora de um contexto de exclusão social (Bonadio \& Mori, 2013; Patto, 1997). O desejo de aprender gestado no vínculo professor-aluno (Guarido, 2007) inclina-se assim a ser reduzido à impersonalidade de um método de ensino matrizado nas neurociências e na padronização de rótulos de criança "preguiçosa", "desinteressada" ou "hiperativa" (Brzozowski \& Caponi, 2013). Desse modo, a atribuição causal endógena acerca das dificuldades escolares resulta compatível com a interpretação imediatista e a-histórica do desenvolvimento infantil (Asbahr \& Lopes, 2006; Paula \& Tfouni, 2009; Proença, 2002) atualmente impulsionada pela lógica medicamentosa (Giusti, 2016; Untoiglich 2014).

\section{Considerações finais}

O debate acadêmico sobre a medicalização da infância e a psicologização da educação nos levou a indagar de que modo a lógica do reducionismo causal da biologização das dificuldades escolares e do esforço e da atenção impregnaria o ideário contemporâneo acerca do desenvolvimento infantil e carregaria efeitos psíquicos identitários nas crianças (como, por exemplo, rótulos, sentimentos de culpa ou incompetência etc.).

A individualização do fracasso escolar não só reduz o papel do outro na construção do conhecimento, mas também reproduz uma perspectiva dicotômica que dissocia a afetividade da inteligência, explicando a dificuldade escolar por fatores emocionais, falta de motivação e/ou esforço individual. Nos materiais indagados observou-se que as tramas significantes prevalentes sobre a dificuldade escolar nos discursos dos adultos tendem a reforçar a ideia de falta de atenção e concentração para explicar a dificuldade escolar, enquanto as crianças focaram seus problemas em conteúdos escolares. Para os adultos, o esforço da criança seria o modo de superar a dificuldade, entretanto, a literatura colocou o problema de que se mostrar pouco esforçado pode resultar em um mecanismo de defesa diante do sentimento de inferioridade no plano da capacidade, para assim manter uma boa imagem de si perante o olhar do outro e de si mesmo. As crenças dos adultos acerca do que é "ser bom filho", "ser bom aluno" e "ser inteligente" validam e legitimam as ideias que as crianças constroem sobre si mesmas. O discurso médico e escolar tende a enriquecer as crenças parentais oferecendo significados que direcionam as explicações da dificuldade em torno da criança, especialmente com base em termos como problemas de atenção e concentração, bloqueios afetivos ou transtornos da aprendizagem. 
"Ir mal na escola" pode resultar em uma das primeiras feridas narcisistas e marcas sociais de exclusão. Como afirma Schlemenson (2009), durante a infância a escola constitui o principal espaço social onde as habilidades e limitações individuais ficam publicamente expostas. A expressão "crianças que não aprendem" costuma ser referida no caso de crianças com dificuldades escolares. Contudo, mesmo sem aprender matemática ou português, na escola elas aprendem modos de se relacionar com os outros, de se defender ou se submeter a situações de exposição e a desenvolver formas mais ou menos sofisticadas de ocultar suas dificuldades ou deixá-las passar despercebidas, o que traz impactos na sua vida intra e extraescolar, presente e futura.

Em resumo, e em concordância com os achados apresentados na literatura, os resultados aqui expostos verificaram que as tramas significantes prevalentes sobre o "não aprender" centram-se na criança; por um lado, com base nas crenças de ser pouco esforçada ou de ter um suposto déficit de atenção, que simplificam a coconstrução da dificuldade escolar. Essa ênfase no esforço ou atitude como modo de compensá-la inibe intervenções mais sistêmicas e menos reducionistas. Evidenciou-se aqui que, por trás das porcentagens e estatísticas do grande guarda-chuva do "fracasso escolar", há crianças construindo uma história singular permeada por expectativas e enunciados que as definem como boas alunas, inteligentes e esforçadas, ou o contrário disso. As crianças falam, mas ao mesmo tempo "são faladas" por outros.

A leitura unívoca e exacerbada do esforço infantil enfraquece o papel dos adultos e oculta a força das políticas públicas implicadas nesse processo. Essa simplificação da queixa escolar promove sentimentos de inferioridade e impotência tanto nas famílias e professores como nas crianças, o que favorece a patologização do aprender e sua interpretação naturalista enquadrada pelas coordenadas da medicalização. Nesse sentido, torna-se necessário realizar mais pesquisas que indaguem as ressonâncias das leituras meritocráticas do fracasso escolar nas interpretações dos professores, dos alunos e das famílias, para assim planejar intervenções mais eficientes e sistêmicas no atendimento da queixa escolar.

\section{Referências}

Alves, M. T. G., \& Soares, J. F. (2013). Contexto escolar e indicadores educacionais: condições desiguais para a efetivação de uma política de avaliação educacional. Educação e Pesquisa, 39(1), 177-194.

Aquino, J. G. (1997). O mal-estar na escola contemporânea. In J. G. Aquino (Org.), Erro e fracasso na escola (pp. 91-110). São Paulo, SP: Summus.

Arbisio, C. (2007). L'enfant de la période de latence. Paris: Dunod. (Trabalho original publicado em 1997)

Asbahr, F. S. F., \& Lopes, J. S. (2006). A culpa é sua. Psicologia USP, 17(1), 53-73.

Bernardeau, C., Devaux, M. C., Josso-Faurite, C., \& Scalabrini, J. (2014). Le groupe logico-mathématique: une fabrique du nombre pour enfants présentant des troubles d'apprentissage des mathématiques. Bulletin de Psychologie, 2(530), 143-147.

Bianchi, E., \& Faraone, S. A. (2015). El trastorno por déficit de atención e hiperactividad (TDA/H). Tecnologías, actores sociales e industria farmacéutica. Physis: Revista de Saúde Coletiva, 25(1), 75-98.

Bianchi, E., Ortega, F., Faraone, S., Gonçalves, V., \& Zorzanelli, R. T. (2016). Medicalización más allá de los médicos: marketing farmacéutico en torno al trastorno por déficit de atención e hiperactividad en Argentina y Brasil (1998-2014). Saúde e Sociedade, 25(2), 452-462.

Bonadio, R., \& Mori, N. N. R. (2013). OTDAH para a comunidade escolar. In: R. A. A. Bonadio \& N. N. R. Mori, Transtorno de déficit de atenção/hiperatividade: diagnóstico da prática pedagógica (pp. 181-219). Maringá, PR: Eduem.

Brzozowski, F. S., \& Caponi, S. N. C. (2013). Medicalização dos desvios de comportamento na infância: aspectos positivos e negativos. Psicologia: Ciência e Profissão, 33(1), 208-221.

Bzuneck, J. A., \& Sales, K. F. S. (2011). Atribuições interpessoais pelo professor e sua relação com emoções e motivação do aluno. Psico-USF, 16(3), 307-315.

Cabanach, R. G., \& Arias, A. V. (1998). Características afectivo-motivacionales de los estudiantes con dificultades de aprendizaje. InV. Bermejo \& J. A. B. Llera (Orgs.), Dificultades de aprendizaje (pp. 261-278). España: Editorial Síntesis. 
Carneiro, G. R., Martinelli, S. C., \& Sisto, F. F. (2003). Autoconceito e dificuldades de aprendizagem na escrita. Psicologia: Reflexão e Crítica, 16(3), 427-434.

Carvalho, S. R.; Rodrigues, C. C. O., Costa, F. D., \& Andrade, H. S. (2015). Medicalização: uma crítica (im)pertinente? Physis: Revista de Saúde Coletiva, 25(4), 1251-1269.

Castro, T. G., Abs, D., \& Sarriera, J. C. (2011). Análise de conteúdo em pesquisas de Psicologia. Psicologia: Ciência e Profissão, 31(4), 814-825.

Ceardi, A., Améstica, J. M., Núñez, C. G., López, V., \& Gajardo, J. (2016). El cuerpo del niño como trastorno: aproximaciones discursivas al abordaje del TDAH. Athenea Digital, 16(1), 211-235.

De-Nardin, M. H., \& Sordi, R. O. (2007). Um estudo sobre as formas de atenção na sala de aula e suas implicações para a aprendizagem. Psicologia \& Sociedade, 19(1), 99-106.

Dubet, F. (2005). La escuela de las oportunidades ¿Qué es una escuela justa? Barcelona: Gedisa.

Dweck, C. (2015, 23 de setembro). Growth Mindset, Revisited. Education Week Articles. https://www.edweek.org/ ew/articles/2015/09/23/carol-dweck-revisits-the-growth-mindset.html

Fernandes, C. T., Muniz, C. A., Mourão-Carvalhal, M.I., \& Dantas, P. M. S. (2015). Possibilidades de aprendizagem: reflexões sobre neurociência do aprendizado, motricidade e dificuldades de aprendizagem em cálculo em escolares entre sete e 12 anos. Ciência \& Educação (Bauru), 21(2), 395-416.

Fernández, A. (2012). A atenção aprisionada: psicopedagogia da capacidade atencional. Porto Alegre, RS: Penso.

Feschler, A. (2012). El superyó del niño y la crueldad en la escuela. Imago Agenda. http://www.imagoagenda.com/ articulo.asp?idarticulo $=1748$

Garbarino, M. I. (2017). Construção do prazer de pensar e desenvolvimento: um estudo teórico-clínico com crianças em dificuldade escolar. (Tese de doutorado). Instituto de Psicologia, Universidade de São Paulo, São Paulo, SP, Brasil.

Giusti, K. G. (2016). A medicalização da infância: uma análise sobre a psiquiatrização da infância e sua influência na instituição escolar (Dissertação de mestrado). Universidade Federal de Santa Catarina, Florianópolis, SC.

Guarido, R. (2007). A medicalização do sofrimento psíquico: considerações sobre o discurso psiquiátrico e seus efeitos na educação, Educação e Pesquisa, 33(1), 151-161.

Jacob, A., Loureiro, S. R., Marturano, E. M., Linhares, M. B. M., \& Machado, V. L. S. (1999). Aspectos afetivos e o desempenho acadêmico de escolares. Psicologia: Teoria e Pesquisa, 15(2), 153-162.

Leavy, P. (2013). ¿ ¿rastorno o mala educación? Reflexiones desde la antropologia de la niñez sobre un caso de TDAH en el ámbito escolar. Revista Latinoamericana de Ciencias Sociales, Niñez y Juventud, 11(2), 675-688.

Lenoble, É. (2010). La langue à l'épreuve du scolaire: que nous apprennent les enfants en mal de lecture et d'écriture? Enfances \& Psy, 2(47), 128-140.

Machado, A. M. (1997). Avaliação e fracasso: a produção coletiva do fracasso escolar. In J. G. Aquino (Org.), Erro e fracasso na escola (pp. 73-79). São Paulo, SP: Summus.

Martinelli, S. C., \& Grecci Sassi, A. (2010). Relações entre autoeficácia e motivação acadêmica. Psicologia: Ciência e Profissão, 30(4), 780-791.

Martínez Álvarez, D. B. (2007). La escuela de las oportunidades. CPU-e, Revista de Investigación Educativa, (5), 1-8.

Martini, M. L., \& Del Prette, Z. A. P. (2002). Atribuições de causalidade de professoras do ensino fundamental para o sucesso e o fracasso escolar dos seus alunos. Interação em Psicologia, 6(2), 149-156.

Mazer, S. M., Bello, A. C. D., \& Bazon, M. R. (2009). Dificuldades de aprendizagem: revisão de literatura sobre os fatores de risco associados. Psicologia da Educação, (28), 7-21.

Nogueira, C. M. M., \& Nogueira, M. A. (2002). A sociologia da educação de Pierre Bourdieu: limites e contribuições. Educação \& Sociedade, 23(78), 15-35.

Observatorio Argentino de Drogas (2008). La medicalización de la infancia. Niños, escuela y psicotrópicos. Buenos Aires: Sedronar. http://www.observatorio.gov.ar/media/k2/attachments/LaZMedicalizacinZdeZlaZInfancia. ZNiosZEscuelaZyZPsicotrpicos.ZAoZ2008.-.pdf 
Ochoa, M. P., \& Orbeta, C. T. (2017). Discursos sobre clase social y meritocracia de escolares vulnerables en Chile. Cadernos de Pesquisa, 47(164), 496-518.

Osti, A., \& Brenelli, R. (2013). Sentimentos de quem fracassa na escola: análise das representações de alunos com dificuldades de aprendizagem. Psico-USF, 18(3), 417-426.

Paín, S. (2010). Diagnóstico y tratamiento de los problemas de aprendizaje. Buenos Aires: Nueva Visión.

Patto, M. H. S. (1997). Para uma crítica da razão psicométrica. Psicologia USP, 8(1), 47-62.

Paula, F. S., \& Tfouni, L. V. (2009). A persistência do fracasso escolar: desigualdade e ideologia. Revista Brasileira de Orientação Profissional, 10(2), 117-127.

Piaget, J. (2005). A representação do mundo na criança. São Paulo, SP: Idéias \& Letras. (Trabalho original publicado em 1926)

Piaget, J. (2005). Inteligencia y afectividad. Buenos Aires: Aique. (Trabalho original publicado em 1954)

Piaget, J. (1977). A tomada de consciência. São Paulo, SP: Melhoramentos.

Polydoro S., \& Azzi, G. R. (2008). Auto-regulação: aspectos introdutórios. In: A. Bandura, R. G. Azzi, \& S. Polydoro, Teoria social cognitiva: conceitos básicos (pp. 9-23). Porto Alegre, RS: Artmed.

Proença, M. (2002). Problemas de aprendizagem ou problemas de escolarização? Repensando o cotidiano escolar à luz da perspectiva histórico-crítica em psicologia. In M. K. Oliveira, D. T. R. Souza, \& M. T. Rego (Orgs.), Psicologia, educação e as temáticas da vida contemporânea (pp. 177-196). São Paulo, SP: Moderna.

Rosa, M. D. (2013). Imigração forçada: a dimensão sócio-política do sofrimento e a transmissão da história. In M. Rosa, T. T. Carignato, \& S. L. S. Alencar (Orgs.), Desejo e política: desafios e perspectivas no campo da imigração e refúgio (pp. 83-98). São Paulo, SP: Max Limonad.

Sabina R., B., Saéz, Z., \& Roméu E., M. (2010). Factores de riesgo asociados a trastornos en el aprendizaje escolar: un problema sociomédico. MediSur, 8(4), 30-39.

Sadalla, A. M. F. A. (1998). Com a palavra a professora: suas crenças, suas ações. Campinas, SP: Alínea

Schlemenson, S. (2009). La clínica en el tratamiento psicopedagógico. Buenos Aires: Paidós.

Silva, J., Beltrame, T. S., Viana, M. S., Capistrano, R., \& Oliveira, A.V. P. (2014). Autoeficácia e desempenho escolar de alunos do ensino fundamental. Psicologia Escolar e Educacional, 18(3), 411-420.

Sisto, F., \& Martinelli, S. (Orgs.). (2006). Afetividade e dificuldades de aprendizagem: Uma abordagem psicopedagógica. São Paulo, SP: Vetor.

Stiglitz, J. E. (2012). El precio de la desigualdad. Barcelona: Taurus

Untoiglich, G. (2014). Medicalización y patologización de la vida: situación de las infancias en latinoamérica. Nuances: Estudos sobre Educação, 25(1), 20-38.

Weiner, B. (1985). An attributional theory of achivement motivation and emotion. Psycological Rewiew, 92(4), 548-573.

Zaro, M. A., Rosat, R. M, Ribeiro Meireles, L. O., Spindola, M., Azevedo, A. M. P., Bonini-Rocha, A. C., \& Timm, M. I. (2010). Emergência da Neuroeducação: a hora e a vez da neurociência para agregar valor à pesquisa educacional. Ciências \& Cognição, 15(1), 199-210.

Zulueta, A. L. (2010). Logros y fracasos de la latencia como parámetros del diagnóstico clínico. Psicopatología y Salud Mental, 16, 21-28.

\section{Mariana Inés Garbarino}

Professora substituta do curso de Pedagogia, no Departamento de Educação da Universidade Federal de São Paulo, Guarulhos - SP. Brasil.

E-mail: marianaigarbarino@gmail.com

(1) https://orcid.org/0000-0003-3013-909X 
Endereço para envio de correspondência:

Universidade Federal de São Paulo. Estrada do Caminho Velho, 333. Sala de Professores 124, Jardim Nova Cidade. CEP 07252-312, Guarulhos - SP. Brasil.

Recebido 22/04/2018

Aceito 13/03/2019

Received 04/22/2018

Approved 03/13/2019

Recibido 22/04/2018

Aceptado 13/03/2019

Como citar: Garbarino, M. I. (2020). O Discurso Meritocrático nas Explicações Parentais de Crianças com Queixa Escolar. Psicologia: Ciência e Profissão, 40, 1-17. https://doi.org/10.1590/1982-3703003195858

How to cite: Garbarino, M. I. (2020). The Meritocratic Discourse in the Parental Explanations of Children with School Complaints. Psicologia: Ciência e Profissão, 40, 1-17. https://doi.org/10.1590/1982-3703003195858

Cómo citar: Garbarino, M. I. (2020). El Discurso Meritocrático en las Explicaciones Parentales de Niños con Queja Escolar. Psicologia: Ciência e Profissão, 40, 1-17. https://doi.org/10.1590/1982-3703003195858 